\title{
Analysis of Electricity Consumption Elasticity Coefficient of Some Countries in ASEAN
}

\author{
Shaomei Yang ${ }^{\mathrm{a}}$, Ting Wang ${ }^{\mathrm{b}, *}$ \\ Department of Economics and Management, North China Electric Power University, Baoding, \\ China \\ ${ }^{a}$ Email:yangshaomei77@126.com \\ bEmail:2630945942@qq.com \\ *Corresponding author
}

Keywords: Fixed base electric elasticity coefficient, Electricity consumption, National economy, One Belt and One Road.

Abstract: Under the trend of economic globalization and conforming to China's "One Belt and One Road" construction strategy, this paper analyzes the characteristics and laws of the changes in the elasticity coefficient of electric power in the Philippines and Indonesia. This analysis is conducive to reflecting the relationship between national economic and social development and electricity demand, providing an effective means for analyzing and predicting the future economic development trends of various countries, and also providing a strong basis for investment countries to make economic and power direction investment.

\section{Introduction}

With the implementation of China's "One Belt and One Road" strategy, it is particularly important to understand and analyze the economic development trends of ASEAN countries. Electricity is the main energy source of the national economy, and it is an indispensable material condition for the modern society's economic operation and people's lives. There is an inseparable link between electricity development and economic development. The elasticity coefficient of electricity consumption has always been applied as a macroscopic relationship between electricity development and economic development. It is an important variable in many quantitative relationships in the national economy. Its changes are economic growth, structural changes, technological progress and supply and demand in a given period. The result of the joint action of related factors such as relations ${ }^{[1]}$ reflects the strength of economic development on the development of electric power in a certain period of time. It is one of the important factors to be considered in formulating long-term electric power development planning ${ }^{[2]}$.

\section{Understanding of the elasticity coefficient of power consumption.}

\subsection{Definition and connotation of power consumption elasticity coefficient.}

Elasticity theory was pioneered by Cournot, a French economist in the 19th century, and later 
used by British and U.S. economists. Flexibility analysis is an easy-to-understand quantitative forecasting method. Elasticity, also known as elasticity coefficient, is a relative quantity that quantitatively describes the relative change of one variable and the relative change of another variable $^{[3]}$. The elasticity coefficient of electricity consumption refers to the ratio of the growth rate of electricity consumption of a country (region) to the growth rate of GDP (economic growth rate), which shows that the growth rate of electricity consumption and the rate of growth of the national economy are fast and slow. Therefore, the connotation of the elasticity coefficient of electricity consumption is reflected. What is the relationship between electricity consumption and economic growth, that is, at a certain rate of economic growth, the growth rate of electricity consumption is ahead of schedule, synchronized, lagging, or negative growth.

According to the above definition, the expression of the power consumption elasticity coefficient $(\mathrm{k})$ is:

$$
\mathrm{k}=\frac{\Delta \mathrm{E} / E}{\Delta \mathrm{G} / G}
$$

In formula (1), $\Delta \mathrm{E}$ denotes the increment of electricity consumption in the current year; $\mathrm{E}$ denotes the total amount of electricity consumption in the previous year; $\Delta \mathrm{G}$ denotes the increment of the GDP in the current year; G denotes the total amount of gross production in the previous year.

In the traditional elasticity coefficient of electricity consumption, both the growth rate of electricity consumption and the growth rate of GDP are the growth rates compared with the previous year. The calculated elasticity coefficient is relatively small in the historical range, and the fluctuation range of the data is large, which is not conducive to Quantitative analysis. The elasticity coefficient of the power consumption of the fixed base converts the growth rate of the electricity consumption of each industry and the growth rate of GDP by selecting the base period, which overcomes the shortcomings of the traditional elasticity coefficient of electricity consumption ${ }^{[4]}$. Therefore, this paper introduces the base-based power elasticity coefficient to study and analyze the relationship between electricity and economic development in the Philippines and Indonesia.

The base elasticity coefficient of electricity consumption is calculated by selecting the base period (in this paper, 2000) and at the same time converting the growth rate of the electricity consumption of each industry and the actual growth rate of the industry GDP, and then dividing the two to obtain the electricity elasticity coefficient of the fixed base electricity consumption ${ }^{[5]}$. Fixed base electricity consumption power elasticity coefficient

$$
\mathrm{e}=\frac{\left(E_{t}-\mathrm{E}_{0}\right) / E_{0}}{\left(\mathrm{G}_{t}-\mathrm{G}_{0}\right) / \mathrm{G}_{0}}=\frac{E_{t} / \mathrm{E}_{0}-1}{\mathrm{G}_{t} / \mathrm{G}_{0}-1}
$$

In the formula: $E_{t}, E_{0}$ are respectively the actual value of electricity consumption of $t$ year and base period; $G_{t}, G_{0}$ are the annual GDP increase value of $t$ year.

\subsection{General Rules of Change in Elasticity of Electricity Consumption}

Although the elasticity of electricity consumption is difficult to predict accurately because of the influence of many factors, according to the analysis of relevant theories and actual data, some general rules of its changes can still be found.

There is a certain relationship among electricity consumption and economic growth, but it is not a completely related functional relationship. In addition to the impact of economic growth, power consumption growth is also affected by factors such as changes in industrial structure, changes In the internal structure of industries, changes in energy consumption structure, and improvements in living standards ${ }^{[6]}$.

The theory of energy economics holds that the elasticity coefficient of electricity consumption generally fluctuates up and down, and has a tendency to approach 1 in general. Of course, specific to a certain period or year, due to the effect of various factors, the elasticity coefficient of electricity 
consumption also mutates and does not follow the law of gradual change.

Judging from the actual situation at home and abroad, in the mid-industrialization stage of "heavy industrialization", the elasticity coefficient of electricity consumption is generally greater than 1; when it develops to the stage of "higher processing," the elasticity coefficient of electricity consumption will decrease. It will float around 1 and tend to be less than 1 ; when it reaches the later stage of industrialization, due to the adjustment of economic structure and the improvement of energy utilization efficiency, the elasticity coefficient of electricity consumption will be less than $1^{[7]}$.

When major economic structural adjustments such as adjustment of industrial structure, adjustment of product structure, and adjustment of employment structure occur, they will generally cause large fluctuations in the elasticity coefficient of electricity consumption ${ }^{[8]}$.

\section{Application of power consumption elasticity coefficient.}

\subsection{The Structure of the GDP Sector and the Type of Electricity}

The GDP sector structure of the countries in this paper is divided into: agricultural GDP, industrial GDP and service GDP. The types of electricity are divided into: industrial electricity, residential electricity, service industry, and agricultural electricity (this paper does not calculate the electricity consumption of residents). For different types of national development, the proportion of GDP in the department's GDP and the department's electricity consumption are quite different. This article from the association of south-east Asian nations selection in many countries of the economic development has been relatively leading countries in Indonesia and nearly two years fast development of the Philippine national electricity elasticity coefficient contrast analysis.

\subsection{Data Selection}

In order to scientifically and accurately reflect the Philippine national and Indonesian national electricity consumption elasticity coefficients and comprehensively consider the consistency and comparability of data sources, this paper has selected the economic and power data of the Philippines and Indonesia from 2000 to 2015.

\subsection{Calculation Results}

This paper uses the 2000 statistical data as the benchmark data, and converts the base-station power elasticity coefficients of the two countries from 2001 to 2015 based on the formula (2), and sets the base-station power elasticity coefficient for each sector. The results are shown in Table 1 and Table 2 
Table 1 The Philippines' base-based power elasticity coefficient and the various departments' base-based power elasticity coefficient

\begin{tabular}{|c|c|c|c|c|}
\hline \multirow[b]{2}{*}{ year } & \multirow[b]{2}{*}{$\begin{array}{c}\text { Power } \\
\text { consumptio } \\
\text { n elasticity } \\
\text { coefficient. }\end{array}$} & \multicolumn{3}{|c|}{$\begin{array}{c}\text { The power consumption elasticity coefficient of each } \\
\text { department. }\end{array}$} \\
\hline & & $\begin{array}{l}\text { Agricultural } \\
\text { power } \\
\text { consumption } \\
\text { elasticity } \\
\text { coefficient. }\end{array}$ & $\begin{array}{l}\text { Industrial power } \\
\text { consumption } \\
\text { elasticity } \\
\text { coefficient. }\end{array}$ & $\begin{array}{l}\text { Service industry } \\
\text { electricity } \\
\text { consumption } \\
\text { elasticity } \\
\text { coefficient }\end{array}$ \\
\hline 2001 & -1.20 & -3.17 & -1.63 & -2.08 \\
\hline 2002 & 13.86 & -2.67 & 4.74 & 1.87 \\
\hline 2003 & 4.74 & -2.33 & 3.93 & 2.63 \\
\hline 2004 & 1.61 & 9.98 & 1.08 & 0.73 \\
\hline 2005 & 0.87 & 4.46 & 0.68 & 0.53 \\
\hline 2006 & 0.49 & 1.93 & 0.40 & 0.32 \\
\hline 2007 & 0.37 & 1.07 & 0.30 & 0.24 \\
\hline 2008 & 0.30 & 3.32 & 0.28 & 0.23 \\
\hline 2009 & 0.36 & 4.08 & 0.32 & 0.24 \\
\hline 2010 & 0.35 & 3.52 & 0.31 & 0.25 \\
\hline 2011 & 0.30 & 2.38 & 0.31 & 0.23 \\
\hline 2012 & 0.30 & 2.70 & 0.29 & 0.22 \\
\hline 2013 & 0.29 & 3.15 & 0.28 & 0.21 \\
\hline 2014 & 0.29 & 3.34 & 0.29 & 0.21 \\
\hline 2015 & 0.33 & 4.30 & 0.32 & 0.23 \\
\hline
\end{tabular}

Source of data: International Monetary Fund; National Bureau of Statistics of China; International Energy Agency 
Table 2 Indonesia's base-based power elasticity coefficient and various departments' base-based power elasticity coefficient

\begin{tabular}{|c|c|c|c|c|}
\hline \multirow[b]{2}{*}{ year } & \multirow[b]{2}{*}{$\begin{array}{c}\text { Power } \\
\text { consumptio } \\
\text { n elasticity } \\
\text { coefficient. }\end{array}$} & \multicolumn{3}{|c|}{$\begin{array}{l}\text { The power consumption elasticity coefficient of each } \\
\text { department. }\end{array}$} \\
\hline & & $\begin{array}{l}\text { Agricultural } \\
\text { power } \\
\text { consumption } \\
\text { elasticity } \\
\text { coefficient. }\end{array}$ & $\begin{array}{l}\text { Industrial power } \\
\text { consumption } \\
\text { elasticity } \\
\text { coefficient. }\end{array}$ & $\begin{array}{l}\text { Service industry } \\
\text { electricity } \\
\text { consumption } \\
\text { elasticity } \\
\text { coefficient }\end{array}$ \\
\hline 2001 & -2.44 & -3.10 & 0.60 & -2.09 \\
\hline 2002 & 0.54 & 0.55 & -0.04 & 0.49 \\
\hline 2003 & 0.34 & 0.21 & 0.01 & 0.48 \\
\hline 2004 & 0.48 & 0.26 & 0.10 & 0.69 \\
\hline 2005 & 0.49 & 0.34 & 0.10 & 0.76 \\
\hline 2006 & 0.36 & 0.23 & 0.06 & 0.57 \\
\hline 2007 & 0.33 & 0.21 & 0.08 & 0.55 \\
\hline 2008 & 0.30 & 0.18 & 0.09 & 0.55 \\
\hline 2009 & 0.32 & 0.16 & 0.11 & 0.61 \\
\hline 2010 & 0.24 & 0.15 & 0.09 & 0.36 \\
\hline 2011 & 0.23 & 0.15 & 0.07 & 0.33 \\
\hline 2012 & 0.27 & 0.18 & 0.09 & 0.36 \\
\hline 2013 & 0.30 & 0.22 & 0.10 & 0.40 \\
\hline 2014 & 0.34 & 0.24 & 0.10 & 0.44 \\
\hline 2015 & 0.37 & 0.25 & 0.13 & 0.46 \\
\hline
\end{tabular}

Source of data: International Monetary Fund; National Bureau of Statistics of China; International Energy Agency

According to the data in the above table, the country's fixed-base power elasticity coefficient of the Philippines and Indonesia and the industrial base-based power elasticity coefficient line chart are intuitively understood and analyzed. See Figure 1 and Figure 2

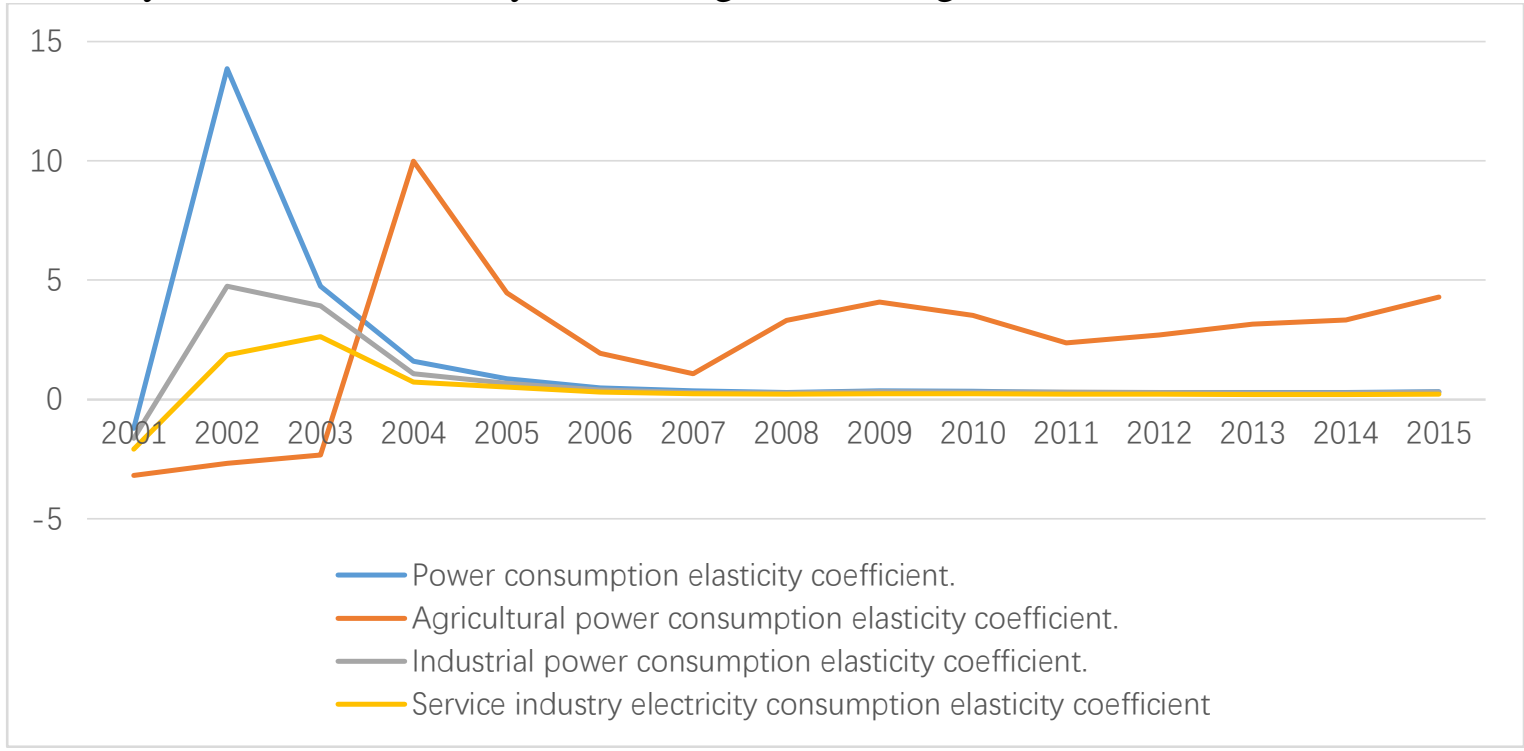

Figure 1 The Philippines' base-based power elasticity coefficient and the base-station power elasticity coefficient 


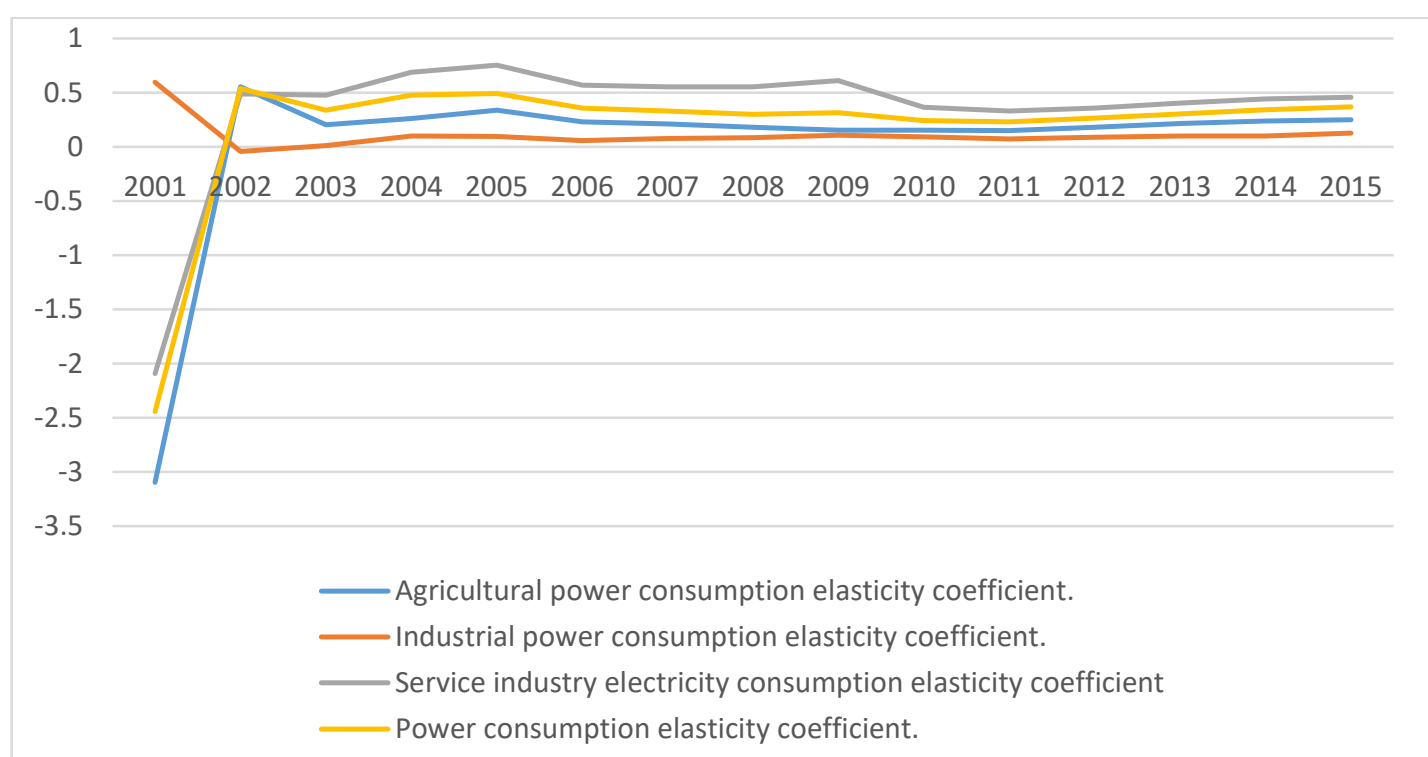

Figure 2 Indonesia's base-based power elasticity coefficient and its sector-based power elasticity coefficient

\section{Discussion and Analysis}

From 2001 to 2005, the Philippines' electricity consumption elasticity coefficient fluctuates greatly; in the period of 2006-2010, the Philippines' electricity consumption elasticity coefficient fluctuates little, and its value is basically maintained at around 0.3. From 2012 to 2015, the Philippine economy achieved rapid growth, with growth rates of $6.68 \%, 7.06 \%$ and $6.15 \%$ respectively. The growth rate of electricity consumption lags behind the economic growth rate. From 2000 to 2015, the proportion of the service industry in the Philippines increased by 7.4\%, the industrial share decreased by 3.7\%, and the proportion of agriculture decreased by $3.7 \%$. In 2016, the proportion of agricultural GDP in the Philippines was 10\%, industrial GDP accounted for 31\%, and service industry accounted for 59\% of GDP. The Philippines is an economic structure driven by the service industry, supplemented by industry, and weakened by agriculture. From 2001 to 2003, due to the negative growth in the growth of electricity consumption in the Philippines, the elasticity coefficient of agricultural electricity consumption in the Philippines was negative; from 2004 to 2015, the elasticity coefficient of agriculture in the Philippines was greater than 1 and significantly higher than the elasticity coefficient of industrial electricity consumption and the service industry. Electricity consumption elasticity coefficient. From 2001 to 2004, the Philippine industrial electricity consumption elasticity coefficient and the service industry electricity consumption elasticity coefficient all fluctuate relatively, and the Philippine industrial electricity consumption elasticity coefficient and the service industry electricity consumption elasticity coefficient fluctuate relatively little from 2007 to 2015. The electricity consumption elasticity coefficient of the Philippines service industry is maintained at $0.21-0.25$; the elasticity coefficient of electricity consumption of the Philippine industry is maintained at 0.28-0.32.

As an emerging economy, Indonesia has undergone a transformation in its economic structure. Agriculture, industry, and service industries have all played an important role in the national economy. In 2015, agriculture accounted for 13.5\%, industry accounted for $40 \%$, and service industry accounted for 46.5. \%. The economic crisis in Southeast Asia that broke out in 1998 brought about a heavy blow to Indonesia's economic development. The Indonesian economy has experienced a severe recession, the currency has depreciated sharply, and GDP has rapidly declined. In 1999, Indonesia entered a slow economic recovery. In 2001, due to the negative economic 
growth in Indonesia, the elasticity coefficient of electricity consumption was negative. From 2002 to 2015, Indonesia's national electricity consumption elasticity coefficient fluctuates less, its value is basically maintained at $0.22-0.54$, and the growth rate of electricity consumption lags behind the economic growth rate. In 2008, when the international financial crisis broke out, the Indonesian economy suffered less, and the economy maintained rapid growth. At this stage, Indonesia's economic structure was different from other countries in East Asia. It was a small number of economies that focused on domestic demand and adopted a number of measures. Promote the development of the domestic market. The coefficient of elasticity of Indonesia's national industrial electricity consumption, except for negative values in 2001, was maintained between 0.15-0.55 in 2002-2015. In addition to negative values in 2002, Indonesia's national agricultural electricity consumption elasticity coefficient was maintained at about 0.1 in 2003-2015. The electricity consumption elasticity coefficient of Indonesia's national service industry, except for a negative value in 2001, was maintained at a value of 0.33-0.76 in 2002-2015.

\section{Conclusion}

The power elasticity coefficient reflects the strength of economic development on the demand for electricity in a certain period. The power elasticity coefficient not only has important guiding significance for the power planning work of various countries, but also provides an effective means for analyzing and predicting the future economic development trends of various countries. Through the calculation and analysis of the fixed-base electric elasticity coefficient and the industry-based electric power elasticity coefficient of the Philippine countries and the Indonesian countries, it provides a strong basis for other investment countries to conduct electricity and economic investment in the Philippine countries and the Indonesian countries.

\section{Acknowledgement}

This work was supported by the Fundamental Research Funds for the Central Universities (NO.2016MS126).

\section{References}

[1] Cai Shuwen. Analysis of Electricity Demand Based on Electricity Consumption Elasticity Coefficient [J]. Social Sciences in Yu Nan, 2007(1):53-57.

[2] He Yongxiu, WEI Jiajia, Cai Qi, et al. Study on Relationship Between Electric Power and Economy Growth in Shanxi Province [J]. North China Electric Power, 2007(4): 1-4

[3] Wang Xueqing, Sun Wu. Analysis of Demand Elasticity Theory and Decision making Applications [J]. Technoeconomics \& Management Research, 2008(3):38-40.

[4] Yu Yi. Study on Power Growth and Industrial Structure Change in Hunan Province [D]. Changsha: Changsha University of Science and Technology, 2010

[5] Luo Guodong. Load Forecasting Based on Improved Electricity Elastic Coefficient Method [J]. Shaanxi Electric Power, 2013, 41(6): 46-48.

[6] Huang Yi, Hu, Erqin, Zheng Lie. On Correlation Between Electricity Consumption and GDP [J]. Journal of Huang gang Normal University, 2010, 30 (3): 119-122 .

[7] Hao Weiping, Li Qionghui, ZhaoYinong. Current Significance of Electricity Elasticity Coefficient in China [J]. Electric Power, 2003, 36(5): 8-10.

[8] Ge Fei, Shi Xuemei, Rong Xiuting. A Study on the Relationship Between the Elastic Coefficient of Power Consumption and Industrial Structure in Anhui Province [J]. Journal of Sichuan University(Social Science Edition), 2015, 30(3): 79-85 . 